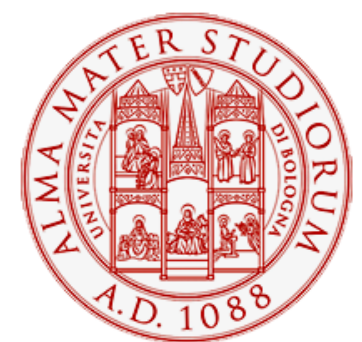

Alma Mater Studiorum - Università di Bologna DEPARTMENT OF ECONOMICS

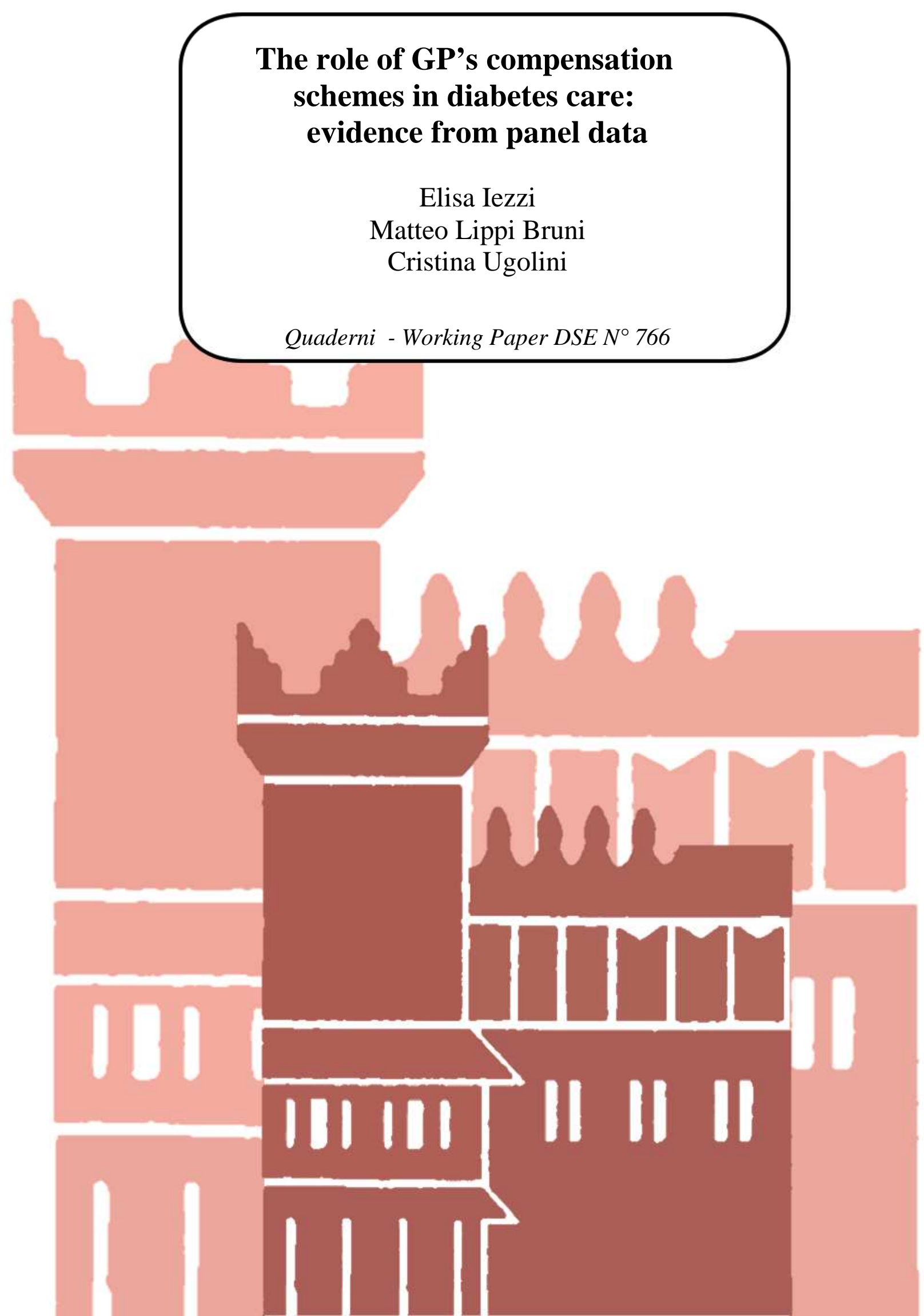




\title{
The role of GP's compensation schemes in diabetes care: evidence from panel data.
}

\author{
Elisa Iezzi*, Matteo Lippi Bruni**, Cristina Ugolini** \\ * Department of Economics, University of Bologna \\ ** Department of Economics University of Bologna and CHILD
}

\begin{abstract}
The design of incentive schemes that improve quality of care is a central issue for the healthcare sector. Nowadays we observe many pay-for-performance programs, where payment is contingent on meeting indicators of provider effort, but also other alternative strategies have been introduced, for example programs rewarding physicians for participation in diseases management plans. Although it has been recognised that incentive-based remuneration schemes can have an impact on GP behaviour, there is still weak empirical evidence on the extent to which such programs influence health outcomes. We investigate the impact of financial incentives in Regional and Local Health Authority contracts for primary care in the Italian Region Emilia Romagna for the years 2003-05. We focus on avoidable hospitalisations (Ambulatory Care Sensitive Conditions) for patients affected by type 2 diabetes mellitus, for which the assumption of responsibility and the adoption of clinical guidelines are specifically rewarded. We estimate a panel count data model using a Negative Binomial distribution to test the hypothesis that, other things equal, patients under the responsibility of GPs receiving a higher share of their income through these programs are less likely to experience avoidable hospitalisations. Our findings support the hypothesis that financial transfers may contribute to improve quality of care, even when they are not based on the ex-post verification of performances.
\end{abstract}

Key words: primary care, quality, diabetes, avoidable hospitalizations, panel count data models.

JEL classification: I11, I18, C31

Correspondence to:

Matteo Lippi Bruni, Piazza Scaravilli 2, 40126, Bologna, Italy.

Tel. +39-051-2098145 - Fax +39-051-2098040.

E-mail: matteo.lippibruni2@unibo.it 


\section{Introduction}

The effectiveness of financial incentives in improving public sector performances has been widely discussed over the last fifteen years and the design of schemes that increase efficiency and quality of services is a common objective for reforms implemented internationally in a number of areas of the public administration. The available evidence indicates that incentives do influence behaviours but not always in the way intended by the scheme's designer (e.g.Burgess and Ratto, 2003). In particular, economic theory suggests that optimal incentives in the public sector should differ from those used in the private sector because dysfunctional and counterproductive behaviours frequently occur, as a consequence of imperfections in measurement indicators, multi-tasking, multiple principals and the presence of intrinsic motivations of workers. For all these reasons, there is rising consensus on the idea that performance related incentives in the public sector should be used very cautiously and lowpowered schemes may represent a viable alternative. Within this context, the health care sector presents some of the most important challenges for measuring public sector productivity, because of its complexity, widespread information asymmetries and considerable risks of unintended side effects of payment schemes (Goddard, Mannion, Smith, 2000; Andersen, 2009). Nevertheless, not only insurance-based systems but also countries with a National Health Service (NHS) have experienced in recent times an extensive introduction of performance based payments for improving quantity and quality of care. Probably, the best known example is the Payment by Results program of the British NHS for financing hospital trusts, but the UK extended target payments also to primary care through the Quality and Outcomes framework (e.g. Campbell et al. 2009, Gravelle, Sutton and Ma 2010; Sutton et al. 2010). The British experience in the area is not unique as proved by the implementation in the Italian NHS of programs that provide General Practitioners (GPs) with extra-payments exceeding standard capitation. These transfers are usually paid to GPs for meeting targets of general interest or for taking part in care improvement activities promoted by public authorities. In NHS systems, the attention to the design of an effective governance of primary care has increased as a consequence of the pivotal role attributed to GPs as providers of ambulatory care, as well as gatekeepers to secondary care. Consequently, public interest focuses not only in improving care quality, but also in involving GPs in strategies aimed at promoting appropriate use of medical services and overall cost containment.

The common purpose of these programs is usually to promote physicians' internalisation of general objectives and the range of activities involved is widely diversified. Special bonuses may be provided for meeting targets that encourage the alignment of GPs' referral and prescription decisions to general health policy goals, usually associated to appropriate use of resources (e.g. containment of hospitalisation rates, prescription of generic drugs, etc...). Nevertheless, financial incentives may reward also direct provision of treatments (e.g. immunisation uptake), assumption of responsibility for patient affected by diseases that require additional physician's effort (e.g. diabetes, hypertension), or 
the adoption of organisational routines aimed at improving cooperation among providers, such as participation in networks of GPs or adherence to evidence-based guidelines.

Another distinction concerns performance monitoring. Pay-for-performance schemes typically tie payments to the achievement of verifiable targets agreed in advance. Alternative approaches may choose to simply reward participation in care improvement activities, without necessarily linking bonuses to the attainment of objectives defined in terms of contracted indicators. The first approach has the advantage of introducing a more stringent incentive structure, aimed at influencing GPs behaviour in the desired direction. Whereas, the second approach is less intrusive of physicians professional autonomy and there are circumstances where it is believed to effectively encourage cooperation between independent providers, such as GPs, and the different actors of the public system.

The array of experiences developed around the world in the area of primary care provides a promising field of investigation for evaluating the effectiveness of a wide set of incentive schemes that pay bonuses on top of standard capitation. Given the variety of possible institutional arrangements, the research agenda has suggested a number of relevant questions for the design of successful policies.

In this paper we analyse diabetes care in the Italian Region Emilia Romagna for the period 2003-2005. Emilia Romagna launched a Diabetes Project in 2003 for improving clinical appropriateness in disease management, through which GPs were assigned the home care responsibility of type 2 diabetic patients. In order to promote the accomplishment by GPs of a number of activities expected to improve quality of diabetes care, Local Health Authorities (LHAs) have been allowed to provide specific compensations to their GPs for activities such as regular reviews of patients, periodic measure of glycosylated haemoglobin, participation to the local diabetes management program. The identification of the activities to be incentivised and the extent of the corresponding financial transfers are bargained between health authorities and the representative organisations of GPs at the district level. Consequently, we record wide differences across districts in the amount of economic incentives. Our measure for quality of care is given by the Ambulatory Care Sensitive Conditions -ACSCsassociated to diabetes. To the extent that hospitalisations for such conditions signal insufficient monitoring and prevention in an outpatient setting, their high frequency can be taken as an indicator of poor quality of primary care (e.g. Billings 1993, Purdy et al. 2009).

The paper tests the hypothesis that, other things equal, the higher the fraction of professional income a GP receives from special payments for diabetes care, the lower the number of avoidable hospitalisations (i.e. diabetic ACSCs) experienced by his type 2 diabetic patients. By doing so, we verify whether physicians respond to economic incentives by improving the quality of care and patient supervision, measured by a reduction in (avoidable) adverse outcomes.

Our work contributes to the literature on the relationship between financial incentives and physician behaviour on several dimensions. First, differently from most of the experiences analysed so far, the incentive scheme implemented in this case is designed at compensating participation in caring 
improvement activities, such as assumption of responsibility of patients, adherence to guidelines etc, rather than rewarding high level of performances. Second, we employ a large panel that covers the entire regional population for three years. The initial study population amounts to 2618087 inhabitants aged 35 or more, from which 164574 diabetic patients are extracted. The use of longitudinal data allows to establish the link between the economic incentives and outcomes of care more precisely with respect to previous studies (Lippi Bruni, Nobilio, Ugolini 2009). In particular, by exploiting variation across time, the effect of financial transfers associated to diabetes care can be more accurately separated from time-invariant individual-specific confounding factors.

\section{The role of financial incentives for health care improvements}

Financial incentives aimed at improving quality of healthcare services are usually designed as pay-forperformance programmes where remuneration is conditional on achieving measurable targets that reflect clearly identified policy goals. Whereas empirical evidence suggests that physicians respond to changes in compensation (e.g. Dumont et al. 2008), studies where quality measures are explicitly introduced are at earlier stages of development. In their recent survey of pay-for-performance programs, Van Herck et al. (2010) find effects that range from negative or absent to positive or very positive, depending on the target and program. Using data from the performance reports of medical groups contracting with a large network HMO before and after implementation of two pay-forperformance schemes in California, Muller et al. (2010) cast doubts on the efficacy of this rewarding mechanism to improve the general quality of health care system and find no evidence of positive spillovers between different clinical areas, even if the size of the bonus could influence the final results. Numerous evaluations have focused on the Quality and Outcomes framework in UK using various methodologies to assess trends in quality indicators before and after introduction of the program in 2004. At this regards, Campbell, Reeves et al. (2009) find an improvement in quality for two of the three chronic conditions considered (diabetes and asthma but not for heart disease) in the short term but, once targets were reached, rates of quality improvement slowed considerably for all the three conditions, whereas continuity and the quality of care for conditions not linked to incentives declined significantly. In their conclusions, the pay-for-performance scheme in the UK initially produced significant improvements in measurable dimensions of clinical performance but such acceleration was not sustained over the subsequent years.

Focusing on diabetes, Scott et al. (2009) find that incentives introduced in Australia in 1999 generated a positive but moderate impact on quality of care in diabetes management, measured by the probability of ordering an HbAlc test. Young et al. (2007) investigate the effect of a program conferring limited financial risk to primary care physicians in Rochester, US, between 1999 and 2004 and find no difference between the post- and pre-intervention trends indicating that the overall increase in performance was largely independent from the incentive program. Examining 47 studies 
testing clinical effectiveness of incentives schemes, the survey of Van Herck et al. (2010) report for diabetes the highest rate of quality improvement due to pay-for-performance implementation.

Some studies suggest that both organization- and physician-level incentives have a measurable impact on quality improvement but also that financial incentives are more influential when based on individual performance. Moreover, physicians' lack of responsiveness may be due to payments that are too small (Conrad and Perry, 2009). In a comprehensive survey, Christianson, Sutherland and Leatherman (2009) conclude that studies with stronger research design report no impacts of financial incentives on quality and so the evidence for justifying the growing use of pay-for-performance schemes is thin and inconclusive.

The empirical literature on payments for quality improvement faces three main challenges. First, incentives schemes are often complicated and nuanced, introduced on top of, or blended with, payment mechanisms aimed to pursue different scopes. This makes difficult to assess the independent effect of the financial scheme. Second, financial incentives can be manipulated owing to the incompleteness of many performance measures, leading to a concentration of efforts only on the areas included in the performance indicator scheme (Gravelle, Sutton and Ma 2010). Third, paying for performance could diminish intrinsic motivation and satisfaction to perform the task for its own sake. A precondition for crowding-out (Frey, 1993; Le Grand, 2003) is that individuals are sufficiently intrinsically motivated. The more important is the task - in the sense that the agent would perform it independently of reward - the more likely intrinsic motivations become. Such relationships are particularly relevant for non-repetitive jobs with high discretion, e.g. physicians motivated by ethics and professionalism. In these contexts, if financial incentives are perceived to trivialize the nonfinancial motivations, their use could be harmful. This could be especially true in NHS systems where monetary incentives could devalue providers altruistic motivation (Siciliani, 2009). ${ }^{1}$ Indeed, as mentioned in the introduction, there are distinct theories on the power of incentives in the public sector as public organizations are endowed with a set of unique characteristics - among others, the lack of markets for goods provided by public organizations and the non-monetary motivations of many public sector employees - that may make it more difficult and less necessary to motivate public employees by paying them according to the value of their output (Andersen, 2009).

Contrariwise, financial incentives could also crowd "in" intrinsic motivation when agents perceive the external rewards as informative or supportive. Bénabou and Tirole (2003) formalize the distinction between intrinsic and extrinsic motivation indicating the importance of both while identifying the

\footnotetext{
${ }^{1}$ As regards the Quality and Outcome framework, McDonald, Harrison et al (2008) report that the financial incentives in the pay-for-performance program have not harmed the internal motivation of GPs; while Campbell, McDonald et al (2008) note that incentives have caused resentment on the part of some nurses about the distribution of bonus payments as they were given responsibility for achieving performance targets. Whalley, Gravelle et al (2008) in a survey of UK physicians find improvements in satisfaction relating to hours worked and remuneration.
} 
overall effect of external interventions on motivation. In their model the crowding out effect is more likely when the reward is offered to agents with limited ability and/or for unattractive tasks. In this case, the agent thinks the principal knows more about his abilities than he himself, so he takes the provision of incentives as a bad sign. In other words, rewards may be weak reinforcers in the short term but they could be counterproductive if they reduced the agent's motivation to undertake the tasks in the future and they become negative reinforcers when they are withdrawn. On the contrary, by offering low-powered incentives or non-contingent payments, the principal could signal his confidence in the agent's ability inducing stronger crowding-in effects. In this case the short-term implications of the principal's confidence-management motive would reduce the slope of the agent's compensation schedule but could strengthen the agent's intrinsic motivation in the long run. Striking a balance between wages, monetary rewards and monitoring is particularly important in the health sector, where production and delivery are highly labour intensive. Indeed, worker motivation is a key determinant of health sector performance where resource availability and worker skills are often necessary but not sufficient to ensure the desired performance.

In addition, theoretical work suggests that low-powered incentives can be optimal when agents allocate effort across multiple tasks some of which are observable only at high costs (Eggleston, 2005). These contracts usually combine an upfront payment (per patient or per unit of time) with a partial fee for service, trying to encourage the provision of features of care (e.g. quality) which are valuable for patients but not easily observable (Dumont et al., 2008). For example, to improve primary care, transfers of a fixed additional amount per chronic patient may help to reduce patients selection and contribute to align physicians' behaviour to the payer's and patient's objectives.

For these reasons, although interest in pay-for-performance mechanisms continues to grow, there are doubts about the ultimate effectiveness of these schemes in the presence of intrinsic motivations and multitasking. An emerging literature extends the general theory of economic incentives introducing concepts from the literature on Public Service Motivation (Andersen, 2009) such as identity with the organization goals, work ethic, non-pecuniary motivations and applying them to the health sector. Meanwhile, many countries such as US, Canada, Australia and New Zealand have been experimenting softer organisational drivers to improve performance, such as delegated autonomy (taking the form of decreased inspection and reporting requirements) and alternative schemes for quality improvements that try to align the interests of the principal with those of the agent by means of a looser incentive structure with respect to pay-for-performance (Smith, 2002; Birkmeier and Birkmeier, 2006; Mannion et al., 2007). The potential advantages of these schemes are providers adherence to evidence based protocols, that help to reduce the risk of developing complications, but also increases in cooperation and coordination between the different actors of the caring process. However, such schemes present also potential shortcomings not to be overlooked, since the lack of binding connections between individual results and financial transfers may attenuate the influence on physicians behaviour. 
Systematic empirical literature on this topic is scarce but outlines that there are cases in which lowpowered incentives may have a positive impact on the quality of care (Dumont et al., 2008).

\section{The organisation of diabetes care}

In Italy, primary care physicians are independent professionals contracted with the NHS on charge of delivering primary care to the citizens registered with them. Moreover, GPs act as gatekeepers to NHS-funded specialist and hospital care. LHAs are divided into Healthcare Districts (HDs) that have the responsibility of organising and coordinating outpatient specialist services, residential and primary care within their territory. Primary care is free at the point of demand and citizens freely choose the GP with whom to register. Although the choice of the GP is reversible at any time, turnover rates are extremely limited and, in most cases, they are a consequence of a change in residence. In year 2000 it was established a maximum list size of 1500 patients. GPs exceeding the limit when the new regulation was approved, were allowed to keep their additional patients but they cannot add new ones until their list has fallen behind the threshold.

Over the last two decades, the Italian NHS has been characterised by a devolution of powers to regional governments which has opened to regions new opportunities for introducing institutional innovations also in primary care. In Emilia Romagna - a north-eastern region with around 4 millions inhabitants - interventions have been carried out in order to further coordination between GPs and LHAs, using also economic incentives to complement the existing GPs' payment scheme based on capitation. In the policymaker's view these financial tools are aimed at promoting a closer alignment of GPs' decisions with general health policy goals. The objectives span from improvements in the quality and appropriateness of care, to the adoption of referral and prescribing decisions expected to back the public payer's effort for cost containment.

The GPs' remuneration scheme is defined every three years in a process of nationally centralized bargaining with GPs' trade unions. The capitation component is the most relevant part of GPs' income paid by the NHS and it is contracted at the national level. Nevertheless, regions have considerable autonomy in defining the additional part of GPs' income and geographical differences over this dimension are documented not only across but also within regions.

The Regional Government can set priorities for primary care but LHAs and HDs benefit of extensive degrees of freedom in defining the activities to be incentivised through additional payments. As regards diabetes care, the Regional Health Authority has started in 2003 a Diabetes Project that defines roles and responsibilities of LHAs, HDs and GPs for disease management, adopts clinical guidelines based on best practices and provides a general framework for introducing specific financial 
incentives $^{2}$. Nevertheless, local agreements between GPs', LHAs and HDs define the extent of additional payments associated to diabetes care. Each agreement involves all GPs operating in a particular district, identifies the activities rewarded and the corresponding financial amount. According to the Regional Diabetes Project, the activities potentially rewarded in each district range from adherence to clinical guidelines to the assumption of responsibility of diabetes patients ${ }^{3}$ or participation in audit meeting. Local diabetes management plans introduce additional payments in a variety of ways. In some cases, as for the assumption of responsibility of patients, GPs receive a financial transfer that increases capitation for each diabetes patient registered in their list. In other cases, as for attendance to audit meetings or contribution to dissemination of new protocols and guidelines, transfers are associated to specific activities promoted at the local level. Consequently, they are not related to the number of diabetes patients followed by each GP.

The main purpose of these programs is to compensate GPs for additional time and effort required for delivering care to diabetes patients and to foster coordination between GPs, HDs and also secondary care facilities. As a consequence of specific local objectives, the agreements signed in each HD display large variability in terms of remunerated activities and in the size of the incentives, but their common purpose is to promote better diabetes management. For this reason we have grouped in a single variable ("financial incentives") all payments received by GPs for the activities aimed at improving the delivery of medical services to diabetes patients. ${ }^{4}$

Our aim is to study the influence of financial incentives on quality indicators for diabetes. For this purpose, the number of diabetic ACSCs represents a good reference for several reasons. First, since the most important avoidable admissions for diabetes are hyperglycaemic emergencies, a reduction in the frequency of these life threatening episodes ensures substantial health gains. Moreover, regular and accurate reviews of patient's conditions together with delivery of appropriate care should be able to avoid such complications. Finally, a reduction in the frequency of diabetic ACSCs or diabetic comas is not explicitly contracted upon in any of the districts that we consider. This ensures that the outcome measure used in the analysis captures a very general dimension of quality and goes beyond the narrow set of activities that are explicitly remunerated. Moreover, we limit the risk of using indicators affected by "tunnel vision effect", according to which professional effort tends to be concentrated only on the

\footnotetext{
${ }^{2}$ Before 2003, there was no formal shared coordination between primary and secondary care but some districts have been experimenting various forms of financial bonus for diabetes since the early $2000 \mathrm{~s}$.

${ }^{3}$ As a consequence of assumption of responsibility, GPs must comply with a range of requirements that include the regular reviews of their diabetes patients, consolidating the patient's knowledge and skills regarding eating plan, physical activity, home blood glucose self-monitoring, foot care etc., reviewing medication usage (oral hypoglycaemic agents or insulin), the periodic measure of their blood pressure and glycosylated haemoglobin (HbAlc), the timely referral to community and hospital based specialists.

${ }^{4}$ In a previous work (Lippi Bruni et al. 2009), for which data only for a single year were available, we consider two variables for financial incentives according to whether transfers were paid on per patient basis or not. Since in several districts the classification of the different items of GPs remuneration has not been fully consistent over time, in the present study based on longitudinal data we prefer to use a unique indicator, which groups together all financial items associated to local diabetes programs.
} 
tasks explicitly remunerated, leading to possible overestimations of the effectiveness of the incentivebased programs.

An important feature of diabetes incentives is that, differently from what happens in other areas of care in the same Region, here additional payments are not linked to strict ex-post monitoring of performance. The main justification relies in the attempt to limit possible drawbacks due to motivation crowding out and reduced willingness to cooperate with public authorities that may be induced by stringent monitoring activities, to the extent that supervision is perceived as intrusive of the patientphysician relationship. Such concerns are particularly relevant in a context where GPs maintain a large professional autonomy in referral and prescribing. Nonetheless, the major shortcoming of such schemes is that the associated incentive structure may be too weak and fail to generate substantial improvements in the patterns of care.

Given these premises, it is an open issue whether programs with these characteristics can ensure health gains to the population of the chronically-ill patients they address. For this reason, an empirical evaluation may prove useful for the design of effective programs also in other contexts.

\section{Methods}

\subsection{Data}

The sources for this study are regional databanks including detailed information on the sources of GPs professional income and on the use of healthcare services by all regional patients (episodes of hospitalisation, prescription of drugs etc...). The initial study population consists of all regional patients affected by diabetes type 2 followed from 2003 to 2005. Information on drug utilisation and access to specialised centres allows to identify patients suffering from diabetes type 2 . According to WHO criteria, patients are classified as having type 2 diabetes if they were aged 35 or more at the time of diagnosis or if they are not currently treated with insulin. Consequently, we include all individuals above 35 years who had at least one prescription for diabetes medications (oral agents or insulin) during 2003. As some patients managed through a diet and exercise alone can be missed with this strategy, we also include individuals who had at least one outpatient visit to a diabetic centre during 2003 or an hospital admission with a diabetic diagnostic code in the previous two years. During the period 2003-05 the average number of GPs active each year amount to 2990 .

Comprehensive information on economic incentives received by each GP, who are linked also to the hospitalisation records of their listed patients, permits us to investigate the relation between bonuses received by GPs for improving diabetes care and health outcomes of their diabetic patients.

It is well documented in the clinical literature on diabetes mellitus type 2 that timely and accurate ambulatory care should be able to prevent deterioration of patient's health status that can ultimately lead to emergency hospitalisation (ADA, 2002; Booth and Fang, 2003; Ices 2003; Fleming 2004, 
RACGP, 2009) In particular, we measure quality of diabetes care with the Ambulatory Care Sensitive Conditions (ACSCs) developed by Billings et al. (1993) for this chronic disease. According to the literature on ACSCs (Purdy et al. 2009), a high frequency of hospital admissions for such episodes is typically associated to deficiencies in disease management and inadequate patient supervision, as appropriate outpatient care should be effective in preventing complications and therefore hospital admission. ${ }^{5}$ The main variable used as quality indicator is the number of yearly hospitalisations for diabetic ACSCs occurring in each GP list among patients affected by diabetes type 2. Hospitalisations for diabetic ACSCs are identified from hospital records when ICD-9 codes 250.1, 250.2, 250.3, 250.4, $250.5,250.6,250.7,250.8,250.9,250.0,251$ are documented as primary or most responsible diagnosis. Following the indications of the Agency for Healthcare Research and Quality for prevention quality indicators (AHRQ, 2007), it is also possible to construct two distinct dependent variables, that distinguish between long-term and short-term diabetes complications. The first group include renal, eye, neurological and circulatory disorders that are thought to arise from sustained longterm poor disease management. The second group includes diabetic ketoacidosis, hyperosmolarity and coma, that are considered life-threatening emergencies arising from the imbalance of glucose and insulin. Given the importance of preventive activities performed in an outpatient setting, these indicators are usually interpreted as proxies for quality of primary rather than of inpatient care. Table 1 displays the frequency distribution for total, long-term and short-term ACSCs. The total number of adverse outcomes in the observation period is 26827 , averaging to 8942 hospitalizations per year, of which 7874 are the yearly hospital admissions for long-term complications and 1068 are the hospital admissions for short-term complications. As expected, the sample displays a high fraction of zero outcomes: $60 \%$ zeros on the total amount of hospital admissions referred to our diabetic population ( $60 \%$ considering long-term complications and $73 \%$ for short-term complications).

\section{TABLE 1}

Table 2 presents descriptive statistics for the estimated sample. For GPs we include gender, seniority and whether the GP has a postgraduate qualifications in endocrinology. We also control for rural practice location and for practice type, distinguishing single-handed from group practices ${ }^{6}$. As regards patients list, we consider size, average patients' age and the number of diabetic patients. Other characteristics of the list are the number of insulin dependent patients and number of visits to a diabetic outpatient clinic (DOC), which are expected to capture severity.

\footnotetext{
${ }^{5}$ For example, ACSCs include short -term complications of diabetes mellitus such as diabetic ketoacidosis, hyperosmolarity, and coma. These life-threatening emergencies arise when a patient experiences an excess of glucose (hyperglycemia) or insulin (hypoglycemia) but with timely and high-quality outpatient care hospitalization for these severe conditions should be preventable.

6 The dummy variable "single handed practices" included in the model identifies the GPs working individually with no established formal connections with other professionals, whereas the reference case for our estimates is represented by the GPs who have set formal agreements with other colleagues (i.e. no-single handed practices). These agreements range from mere coordination of practice opening hours to substitutions in case of illness. But a more intense cooperation can also be implemented, such as sharing premises of the practice, nursing staff and/or clinical information. Nevertheless, even when GPs build up such networks, the lists of patients are managed separately by each GP.
} 


\section{TABLE 2}

The variable financial incentives include rewards received by GPs for assumption of responsibility for each diabetic patient registered in their list and payments for participation in improvement activities or for compliance with regional and local guidelines. In our analysis, financial incentives are included as share of annual income paid to each GP by the Regional Health Authority. Figure 1 shows the distribution of such incentives across the 13 Local Health Authorities. To account for supply side characteristics, we include also the number of per capita hospital beds and the number of per capita beds in endocrinology. In addition, as an indicator of market structure, we construct a competition index, calculated as the number of district GPs per 1000 inhabitants (Kann, Biørn, Luras, 2010). As additional proxy of geographical accessibility we consider also population density. All four controls are entered at the district level, which is the smallest institutional dimension within the present system. Nevertheless to account for more general common policy factors we include geographical dummies for the three macro areas ("vast areas") in which the Region is divided and that group together neighbouring LHAs. These "vast areas" represent the main institutional entities where top down processing and coordination of health care policies is implemented. ${ }^{7}$

\section{FIGURE 1}

\subsection{Statistical analysis}

In our study the count variable $y$ - number of diabetic ACSCs recorded in each GP's list per year- is non-negative and follows a positively skewed distribution of nonzero realisations (Figure 2).

\section{FIGURE 2}

We consider Poisson and Negative binomial regressions. The Poisson distribution is identified by a single parameter $\lambda$, equal for mean and variance, conveniently specified as a log-linear function of the explanatory variables $x_{i}$ that account for observed sample heterogeneity. As a consequence, $\lambda_{i}$ is positive for any combination of $x_{s}$ and $\beta_{s}$ :

$$
E\left(y_{i} \mid x_{i}\right)=\lambda_{i}=\exp \left(\beta_{0}+\sum_{j} x_{i j} \beta_{j}\right)=\exp \left(\mathbf{x}_{i}^{\prime} \boldsymbol{\beta}\right)>0 .
$$

When equidispersion is not satisfied, the negative binomial regression (Hilbe, 2007) is the most commonly used alternative to the Poisson and can be obtained by introducing latent heterogeneity in the conditional mean of the Poisson distribution (Hilbe and Greene, 2008):

$$
E\left(y_{i} \mid x_{i}\right)=\exp \left(\mathrm{x}_{i}^{\prime} \beta+\varepsilon_{i}\right), \quad \operatorname{Cov}[\mathrm{x}, \varepsilon]=0
$$

\footnotetext{
7 In general, catchment areas for major hospital specialties, strategies for self sufficiency -including investment policies in hospital capacity- special arrangements for compensating patients' mobility as well as procurement policies are agreed at the level of vast areas.
} 
To fully characterise the model, distributive assumptions over $\varepsilon$ are required. In the standard negative binomial model (Greene, 2008) $h_{i}=\exp \left(\varepsilon_{i}\right) \stackrel{d}{\longrightarrow}$ Gamma with mean 1 , variance $1 / \theta$ and $f\left(h_{i}\right)=\frac{\theta^{\theta}}{\Gamma(\theta)} \exp \left(-\theta h_{i}\right) h_{i}^{\theta-1}$ with $h_{i}>0, \theta>0$, where $\Gamma($.$) denotes the gamma integral that$ brings to an integer argument.

The marginal distribution of $y$ is a Poisson-gamma mixture with a closed form and the marginal negative binomial (NB) distribution $N B(\lambda, \theta)$ is:

$$
f\left(y_{i} \mid \mathbf{x}_{i}\right)=\frac{\Gamma\left(\theta+y_{i}\right)}{\Gamma(\theta) \Gamma\left(y_{i}+1\right)}\left(\frac{\theta}{\lambda_{i}+\theta}\right)^{\theta}\left(\frac{\lambda_{i}}{\lambda_{i}+\theta}\right)^{y_{i}}
$$

The moments are $E\left(y_{i} \mid \mathbf{x}_{i}\right)=\lambda_{i}$ and $\operatorname{Var}\left(y_{i} \mid \mathbf{x}_{i}\right)=\lambda_{i}+\frac{1}{\theta} \lambda_{i}^{2}$, where $\frac{1}{\theta}$ is a dispersion parameter measuring the extent of overdispersion and the conditional variance is always greater than the conditional mean. The negative binomial model in previous equation is labelled NB2 (Hilbe, 2007) in reference to the appearance of quadratic term for $\lambda_{i}$ in the conditional variance function. The generalized event count model is NBP for which NB1 and NB2 represent special cases with $\mathrm{P}=1$ and $\mathrm{P}=2 .^{8}$

We employ a likelihood ratio (LR) test of overdispersion parameter $1 / \theta$ to evaluate the validity of the Poisson specification against the negative binomial model $\left(H_{0}: 1 / \theta=0\right)$. Following Greene (2008) as NB1 and NB2, are not nested, we use the Vuong test (1989), whereas we use a LR test for selecting between NB1 and NBP or NB2 and NBP, since these models are nested.

Specifications for nonlinear panel data include pooled, fixed and random effects. A first possibility is simply to ignore time dependence. However, by pooling data together, the estimated standard errors will not be reliable for hypothesis testing. To address the problem, one may use a panel-robust estimate of variance that correct standard errors for dependence over time for any given individual.

Less naïve approaches assume correlation over time $(t=1, \ldots, T)$ for observations pertaining to the same individuals $i(i=1, \ldots, n)$. The fixed effect model incorporate individual heterogeneity with an individual-specific intercept term:

$$
\log \lambda_{i t}=\alpha_{i}+\boldsymbol{\beta}^{\prime} \mathbf{x}_{i t}+\varepsilon_{i t},
$$

where $\alpha_{i}$ can be interpreted as the coefficient of a binary variable taking value 1 for observations belonging to the $i$-th group. This model can be estimated by means of direct maximization of the full log-likelihood function (unconditional estimator) or with conditional maximum likelihood. In general,

\footnotetext{
${ }^{8}$ The conditional variance for the NBP model is $\operatorname{Var}\left(y_{i} \mid \mathrm{x}_{i}\right)=\lambda_{i}+\frac{1}{\theta} \lambda^{P}$, whereas the conditional mean is the same in each NB specification.
} 
the unconditional estimator is preferred because it is consistent in $\mathrm{T}$, where $\mathrm{T}$ is usually assumed to be fixed and small. Simulation studies (Greene, 2006) demonstrate that scaling its standard errors by the deviance-based dispersion statistic produces standard error that are closer to the nominal values (Hilbe, 2007). The alternative is a random effect model such as the following:

$$
\log \lambda_{i t}=\boldsymbol{\beta}^{\prime} \mathbf{x}_{i t}+u_{i}
$$

where $u_{i}$ is an IID random effect for the $i$-th group, the same in every period, such that $\exp \left(u_{i}\right)$ has gamma distributions with parameters $\left(\theta_{i}, \theta_{i}\right)$. Thus, $E\left[\exp \left(u_{i}\right)\right]$ has mean 1 and variance $1 / \theta$. It is usually assumed that $\theta_{i} /\left(1+\theta_{i}\right)$ is distributed as Beta $(a, b)$. The random effect is added to the NB model by assuming that overdispersion parameter is randomly distributed across groups, with a loglikelihood function that is $L\left(\beta ; y_{i t}, a, b\right)$. This model can be estimated by a direct maximization of the full log-likelihood function.

\subsection{Specification tests}

First, we employ a LR test to check whether a count model assuming equidispersion is an adequate specification. Under $H_{0}$, imposing restrictions in estimated parameters should make little difference to the maximized value of the likelihood function. The LR statistic is displayed in Table 3 and, as expected, rejects the Poisson in favour of the Negative binomial (NB2) specification.

For choosing the appropriate NB specification, we first compare NB2 and NB1, using the Vuong (1989) statistic: $V=\sqrt{n} \bar{m} / s_{m}$ where $m_{i}=\ln L_{i}(N B 2)-\ln L_{i}(N B 1)$ is the ratio of the logs of the fitted probabilities for the $i-$ th observation under null hypotheses. The test statistic is the standard measure for testing whether a mean is zero and the limiting distribution of Vuong is normal $(0,1)$. Large values favour $\mathrm{H}_{0}$ against a broader alternative $\mathrm{H}_{1}$, but the intermediate values are inconclusive. The critical value (Table3) less than -1.96 suggests the NB2 model is preferred. Further LR statistic for choosing NB1 vs. NBP and NB2 vs. NBP. The LR statistic (Table 3) rejects NB1 specification in favour of NBP, but does not reject the NB2 in favour NBP. The results of the tests support the choice of the NB2 model.

To test for the relevance of correlation across time, we use LR tests for the random effects against the pooled specification with robust standard error. The LR statistic (Table 3) rejects the pooled specification.

\section{TABLE 3}

Finally, a Hausman test is used to choose between fixed- and random-effects. Under the null, both specification are consistent, but the random effect is more efficient. Under the alternative, the random effect specification becomes inconsistent. Thus, if the null hypothesis is verified, the two estimators should be similar; divergence indicates rejection of the null. The statistic is: 


$$
H=\left(\hat{\beta}_{R E}-\hat{\beta}_{F E}\right)^{\prime}\left[\operatorname{Vâr}\left(\hat{\beta}_{R E}\right)-\operatorname{Vâr}\left(\hat{\beta}_{F E}\right)\right]^{-1}\left(\hat{\beta}_{R E}-\hat{\beta}_{F E}\right)
$$

Our test reported at the end of Table 4 produces a $\chi^{2}$ statistic of 196 (p-value $<0.001$ ) Consequently, random-effects are rejected in favour of the fixed-effects.

\section{Results}

In Table 4 and 5 we report estimates for alternative negative binomial specifications. In particular, Table 4 provides results for the total number of diabetes ACSCs whereas Table 5 ( $a$ and $b$ ) distinguishes between long-term and short-term complications.

\section{TABLE 4 -5 a-b}

Our findings are fairly consistent across specifications. Interestingly, even if the Hausman test suggests that FE estimates are to be considered the preferred ones, the differences between the three specifications do not substantially affect the coefficients for financial incentives, our most relevant policy variable.

Individual characteristics of the GP display some effects although they are not systematic. For instance gender is not significant, whereas seniority is significant in the pooled and RE specification but not in the FE one. As for the time invariant GP variables, neither practice type nor rural practice location produce any effect, whereas GPs with post-graduate specialisation tend to hospitalise their diabetic patients for an ACSC more frequently. This may be due either to different practice style, or it may capture unobserved heterogeneity in the patients' case-mix, with more qualified GP attracting relatively more severe patients. Statistically significant effects emerge when we consider the characteristics of the list. This confirms the importance of accurately controlling for differences in the case-mix at the physician level. In particular, the control that most directly reflect severity such as the number of insulin treated patients positively contributes to an increase in hospitalisations in all specifications and for each of the three categories of diabetic ACSCs considered. Moreover total ACSCs and short-term complications are influenced also by the overall number of listed patients diagnosed with diabetes, whereas the average age of the list influences in particular long-term complications.

Patients registered with practices located in densely populated areas display lower expected frequencies of adverse outcomes. A possible explanation is that residents in more heavily populated areas benefit of easier accessibility to the practice and to other outpatient facilities because of shorter travel distance and public transport availability, thus reducing the probability of avoidable hospitalisations. However, once the density effect is accounted for, other proxies for accessibility such as number of visits to diabetic specialised wards or rural practice location do not produce a separate significant impact on any dependent variables. 
The major policy issue addressed in the paper concerns the effectiveness of economic incentives in improving outcomes of diabetic care. In the estimated equations coefficients associated to financial incentives are highly significant and negative for all three dependent variables taken into consideration. Such evidence suggests that ad hoc monetary rewards positively influence outcomes of diabetes care by reducing hospitalisations rates for diabetic ACSCs. Our results show that, after controlling for a set of relevant covariates including physician characteristics and composition of the list, an increase in the share of additional payments received by the GP significantly reduces the expected number of avoidable hospitalisations experienced by patients registered with him. In this case, the additional component of GPs' remuneration seems to be effective for incentivising appropriateness of care and accurate monitoring of diabetic patients, which ultimately is expected to reduce the incidence of adverse outcomes. It is important to remark that in the institutional framework considered here the incentive structure is not based on strict monitoring of individual performances. Moreover, this holds true despite the fact that we measure quality of medical care using indicators, such as avoidable hospitalisations, which, are widely accepted internationally but were not explicitly rewarded in contracts with GPs in the period under consideration.

At this level of the analysis, it may be useful to provide more clear-cut indications on the size of the estimated impact of the scheme under evaluation. To do so, we first estimate marginal effects of the FE NB2 specification at sample averages for all covariates and compute the expected number of ACSCs, which amount in total to a yearly average of 8165 cases (2,869 ACSCs per GP per year). Then, we hypothesise three different scenarios where all variables are kept fixed at the sample averages except financial incentives for diabetes care for which it is hypothesised an increase per GP of 100, 200 and 1000 Euros respectively, Table 6 presents the projections of the estimated reduction in ACSCs in the three different scenarios. When the yearly increase of monetary rewards per GP is limited to 100 Euros, the reduction in ACSCs amounts on the whole to 222 cases Euros for the three year period.

If we hypothesise an increase of 200 euros per GP , the overall reduction in avoidable admissions reaches 303. Further reductions are obtained if we consider the possibility of a much larger increase in the extra amount paid to GPs, as it is the case for the 1000 euro scenario. However, since these projections are based on estimates of marginal effects, the smaller the (simulated) additional financial bonus, the more reliable the projection.

\section{TABLE 6}

\section{Extensions and robustness checks}


In this section we discuss possible extensions of the analysis aimed at testing the robustness of our main conclusions concerning the role for financial incentives. We address four main concerns. First, we consider the relevance of potential non linear effects associated to financial incentives as well to the other continuous variables. Second, we assess whether including a weight for relative severity of episodes of hospitalisation influence our results. Third, following the Hausman and Taylor (1981) approach, we test whether financial incentives are still significant once we relax the assumption of exogeneity of features of the GP list. Finally, we perform a "placebo" test to support our identification strategy. We do it by re-estimating the count data model by using as dependent variable a list of conditions that are not expected to be influenced by the quality of primary care services. By showing that financial incentives do not influence the probability of hospitalisation in the latter case, we can rule out the possibility that the influence of financial incentives on the ACSCs is merely the consequence of a generalised decreasing trend on hospitalisations.

Overall, all these extensions indicate that financial incentives continue to be highly significant, a result which supports the validity of our main conclusion.

\subsection{Non linear effects}

As first check, we re-estimate the model of total diabetes ACSCs to study whether some covariates including financial incentives- display non linear effects. We find some evidence for a quadratic effect only for the variable insulin patients, with a positive sign on the linear term and a negative term on the quadratic term. On the contrary, for financial incentives, the quadratic term is never significant, once all other covariates are accounted for. Table 7 reports the results for the estimates that include the only significant quadratic term (i.e. insulin patients). It is straightforward to check that the inclusion of significant non linear effects do not produce any changes in the estimations of the other coefficients.

\section{TABLE 7}

\subsection{An alternative measure of the dependent variable: DRG expenditures}

A possible limitation of our analysis relying on count data is that, besides the distinction between long and short run complications, the dependent variable does not weight different episodes of hospitalisation according to their relative severity. It is therefore important to check whether the qualitative results are robust to the introduction of indicators that proxy the amount of resources required to treat different cases. For this purpose, we have re-estimated the model using the log of total expenditure for diabetic ACSCs as dependent variable. Expenditure is calculated from the diagnosis 
related group (DRG) assigned to each hospital admission and the monetary value associated corresponds to the tariff set for each DRG by the Regional Health Authority in the period considered. In this case, the dependent variable is continuous and table 8 presents the results for pooled, random and fixed effect panel estimations.

By and large the results of the previous analysis are confirmed also under this new specification of the dependent variable. With the exception of list size, the variables associated to the GP's list (list average age, number of diabetic and insulin treated patients) are significant in all specifications, with fairly robust coefficient. As for the previous case, population density is the only measure of accessibility that has a significant impact on the new dependent variable. Most important of all, the coefficient for financial incentive is still significant in the three alternative specifications (pooled, RE and FE). The sign of the effect is negative as expected and the size of the marginal effect pretty similar across specifications.

\subsection{Potential endogeneity of the list}

In the Italian system of primary care, to the extent that the doctor has not reached the maximum number of listed patients allowed, each citizen is free to enrol with his preferred GP. Therefore, in principle some (unobserved) GP characteristics may attract selected groups of patients in a way that we cannot control for, as they may for instance reflect different practice styles. If this is the case, list related variables may suffer of an endogeneity problem (Kann, Biorn and Luras, 2010). To tackle this issue we follow the approach originally developed by Hausman and Taylor (1981)- H-T henceforth. The H-T panel estimator allows to circumvent the 'all or nothing' assumption of exogeneity of the controls and the random individual effects, which lies behind the choice of the random and fixed effect specification (Baltagi, Bresson, Pirotte, 2003). The main advantage with respect to the random effects specification is that the $\mathrm{H}-\mathrm{T}$ approach relaxes the assumption that all regressors are exogenous, by allowing a non-zero correlation between a subset of covariates and the individual effect. This is obtained by using the averages of the strictly exogenous regressors as instruments for the controls. At the same time, differently from fixed effects, this procedure allows to include in the estimation also time-invariant variables, as its estimates accounts also for cross sectional variation between observations, whereas the fixed effect approach exploits only cross time variability within observations.

In the last column of Table 8 we present H-T estimates that can be compared with findings of the pooled, fixed, and random-effects models. 


\section{TABLE 8}

As already mentioned, the variables reflecting characteristics of the list may be deemed to suffer of potential endogeneity, to the extent that there are non random unobserved factors that influence patients' enrolment decision and, consequently, also the observed composition of the list. If this is the case, (some of the) list characteristics may be correlated with the error component, leading to biased estimates. In the H-T panel specification the following variables are hypothesised potentially endogenous: list size; number of diabetic and of insulin treated patients. As it can easily checked from table 8 , the coefficient of financial incentives is still negative and significant even after relaxing the assumption of exogeneity for all variables of list composition, although the size of the effect is lower than in the previous estimates.

\subsection{The marker conditions}

Finally, a more fundamental criticism could be raised according to which the outlined reduction in diabetic ACSC admissions may reflect a general downward trend in hospitalisations, rather than being the consequence of improved quality of primary care resulting from the introduction of ad hoc monetary incentives. In order to address this objection we perform an "anti-test" (or placebo test) frequently used in health economics. ${ }^{9}$ This strategy consists in re-estimating the same model in a different context, where by construction the relevant policy variables are expected to produce no effect. The test is passed if no influence of the relevant variables is actually found in the new context, otherwise one can cast doubts on the appropriateness of the initial identification strategy.

As placebo variables for the diabetes ACSC admissions, we use a set of "marker conditions" identified by the epidemiological literature. ${ }^{10}$ These marker conditions are indicators of population health for which hospitalisation is not expected to be related to the quality of primary or specialty care, physician supply, physician practice patterns or other related variables. They include hospitalizations for appendicitis with appendectomy, acute myocardial infarction (AMI) ${ }^{11}$, gastrointestinal obstruction and

\footnotetext{
${ }^{9}$ See Jones (2009) for a survey.

${ }^{10}$ For detailed references see Basu and Mobley (2007).

${ }^{11}$ AMI admissions are believed to be preventable in many cases with a long-term program of controlling risk factors, but the view of the advisory panel (Billings et al. 1993) was that most new admissions for AMI were not preventable by the use of primary and preventive services within the several weeks prior to admission.
} 
hip fracture. Compared to preventable conditions, admissions from marker conditions are urgent in nature and not preventable by use of ambulatory care (Billings et al. 1993) ${ }^{12}$. Because of their insensitivity to primary care utilization, they provide an appropriate comparison group for preventable hospitalizations and can be used as robustness check for our identification strategy.

\section{TABLE 9}

As displayed in Table 9, the empirical evidence obtained from the inclusion of marker conditions as dependent variable in our model is consistent with the identification strategy proposed in the paper. Indeed, as expected, we do not detect any significant effect of financial incentives on marker conditions. This result confirms that, when health indicators different from those related to the quality of diabetes care are considered, no influence of the incentive schemes for diabetes is detected on hospitalisation patterns. Such evidence reinforces the view that the negative relationship between financial incentives and diabetic ACSCs does not merely reflect a general trend in hospitalisations, but it genuinely captures the impact of the policy measure.

\section{Conclusions}

In the present paper we have analysed the influence of economic incentives on the quality of primary care. We have focused on diabetes type 2 and we have considered financial transfers provided to GPs with the specific purpose of improving quality of treatment for such disease. Our dataset spans over 3 years (2003-05) and covers the population of diabetic patients and GPs operating in the Italian region Emilia Romagna. By exploiting a comprehensive dataset that links hospital records, pharmaceuticals prescriptions and provides details on GPs remuneration schemes, we have been able to evaluate the association between the performance of GPs in terms of outcome indicators for diabetes care and the share of money that they receive for participating in improvement activities in that specific clinical area.

According to a well established epidemiological literature (Billings et al. 1993), our outcome indicator is expressed as number of avoidable hospitalisations per year for ICD-9CM codes recognized as diabetic ACSCs. As timely and good quality of treatment in a primary care setting should be able to prevent such hospitalisations, this adverse event is an indicator of poor quality of primary care. We estimate a series of panel count data models, where the dependent variable consists of the number of

\footnotetext{
${ }^{12}$ Analogously to diabetic ACSCs, also marker conditions are defined using principal diagnosis codes from the International Classification of Diseases, Ninth Revision (ICD-9-CM ) system (Billings et al. 1993).
} 
diabetic ACSCs recorded in the list of each GP. We control for a set of covariates aimed at capturing differences in size and composition of the list, as well as in individual characteristics of the GP and results are fairly consistent across the different specifications.

Thanks to the availability of panel data which allow to control for hydiosincratic time-invariant effects, we can draw useful insights on the role of economic incentives in the Italian primary care sector, in particular for diabetes management. The longitudinal structure of the data guarantees a more accurate assessment of the impact of financial transfers than previously done in the same institutional context (Fiorentini et al. 2011, Lippi Bruni et al. 2009). The coefficients associated to financial incentives are consistently negative and significant, thus implying that diabetic patients followed by GPs that receive a higher share of their wage through such programs have a lower probability to experience avoidable hospitalisations for diabetes related diseases.

As for (some of) the policy questions investigated by the literature on program evaluation in primary care, our contribution first assesses the effectiveness of programs based on financial incentives in influencing patterns of care. Second, we confirm that, at least for disease specific programs, there are situations where low powered incentives may reach the ultimate goal of improving patients conditions, although ex-post monitoring of performance is not strictly enforced. In the present context, this is obtained by incentivising with additional payments improvements in the quality of care and a more effective cooperation between independent professionals contracted with the NHS, such as the GPs, and the layers of the public healthcare sector.

\section{Acknowledgements}

The study was financed by the Italian Ministry of Scientific Research (MIUR) and the Italian Ministry of Health.

Elisa Iezzi gratefully acknowledges financial support from Fondazione Cassa dei Risparmi di Forlì. The authors thank the Regional Agency for Healthcare Services of Emilia Romagna for making the data available. We thank participants at the following conferences Italian Association of Public Economics (University of Pavia), Health Economics Study Groups (London School of Economics), Applied Health Economics and Policy (IRDES- Paris) and Brigitte Dormont who provided very useful comments on earlier versions of the paper. Usual disclaimers apply.

\section{References}

ADA Clinical Practice Recommendations. Hyperglycaemic crisis in patients with diabetes mellitus. Diabetes Care 2002; 25 (Suppl 1); S100-8. 
Agency for Healthcare Research and Quality. Guide to Prevention Quality Indicators: Hospital Admission for Ambulatory Care Sensitive Conditions. 2007. http://www.qualityindicators.ahrq.gov.

Andersen LB. What determines the behaviour and performance of health professionals? International Review of Administrative Sciences 2009; 75; 79-97.

Baltagi, B.H., Bresson, G. Pirotte, A. (2003), Fixed effects, random effects or Hausman-Taylor? A pretest estimator, Economics Letters, 79, 361-369.

Basu J, Mobley LR. Do HMOs reduce preventable hospitalizations for Medicare Beneficiaries? Medical Care Research and Review 2007; 64 (5); 544-7.

Benabou R, Tirole J. Intrinsic and extrinsic motivation. Review of Economic Studies 2003; 70 (3); 489-520.

Billings J, Zeitel L, Lukomnik J et al. Impact of socioeconomic status on hospital use in New York City. Health Affairs 1993; 12; 162-173.

Birkmeier NJ, Birkmeier JD. Strategies for improving surgical quality - should payers reward excellence or effort? The New England Journal of Medicine 2006; 354 (8); 864-70.

Booth GL, Fang J. Acute complications of diabetes, in Diabetes in Ontario: An ICES Practice Atlas, Hux J, Booth G, Slaughter P, Laupacis A. (eds), ICES, Ontario; 2003.

Burgess S, Ratto M. The Role of Incentives in the Public Sector: Issues and Evidence. Oxford Review of Economic Policy 2003; 19 (2); 285-300.

Campbell SM, McDonald R, Lester H. The experience of pay for performance in English family practice: a qualitative study. Annals of Family Medicine 2008; 6; 228-234.

Campbell SM, Reeves D, Kontopantelis E, Sibbald B, Roland M. Effects of Pay for Performance on the Quality of Primary Care in England. The New England Journal of Medicine 2009; 361; 368-78.

Conrad DA, Perry L. Quality-Based financial incentives in Health Care: Can we improve quality by paying for it? Annual Review of Public Health 2009; 30; 357-71.

Christianson J, Sutherland K, Leatherman S. Financial incentives, healthcare providers and quality improvements: a review of the evidence. QQUIP, The Health Foundation, London; 2009.

Dumont E, Fortin B, Jacquemet N. Shearer B. Physicians' multitasking and incentives: empirical evidence from a natural experiment. Journal of Health Economics 2008; 27; 1436-1450.

Eggleston K. Multitasking and mixed systems for provider payment. Journal of Health Economics 2005; 24 (1); 211-223.

Fleming DM. The prevalence of known diabetes in eight European countries. European Journal of Public Health 2004; 14; 10-14.

Frey B. Shirking or work morale? The impact of regulating. European Economic Review 1993; 37; 1523-32.

Goddard M., Mannion R., Smith P. Enhancing performance in health care: a theoretical perspective on agency and the role of information. Health Economics 2000; 9; 95-107.

Gravelle H., Sutton, M. Ma A. Doctor behaviour under a pay for performance contract: treating, cheating and case finding?, Economic Journal 2010; 120; F129- F156. 
Greene W. LIMDEP Econometric Modeling Guide, Version 9, Plainview, NY:Econometric Software Inc. ; 2008

Greene W. Functional forms for negative binomial model for count data. Economic letters 2008; 99; 585-590.

Hausman J.A., Taylor W.E. Panel Data and Unobservable Individual Effects. Econometrica 1981: 49, 1377-1398.

Hilbe J.M. Negative binomial regression. Cambridge University Press; 2007.

Hilbe J.M, Greene WH. Handbook of Statistics Vol.27, Elsevier BV; 2008.

ICES (Institute for Clinical Evaluative Sciences) and Canadian Diabetes Association. Diabetes in Ontario: an ICES practice atlas; 2003.

Jones A.M, Panel data methods and application to health economics, in Mills TC, Patterson K (eds) The Palgrave Handbook of Econometrics Volume II: Applied Econometrics, Basingstoke, Palgrave MacMillian.

Kann I.G., Biorn E., Luras H. (2010), Competition in general practice: Prescription to the elderly in a list patient system. Journal of Health Economics, 29, 751-764.

Fiorentini, G, Iezzi, E., Lippi Bruni M., Ugolini C. Incentives in primary care and their impact on potentially avoidable hospital admissions, European Journal of Health Economics, forthcoming, 2011.

Le Grand J. Motivation, Agency and Public Policy: of Knights and Knave, Pawns and Queen. Oxford University Press, Oxford; 2003.

Lippi Bruni M, Nobilio L, Ugolini C. Economic incentives in general practice: the impact of pay-forparticipation and pay-for-compliance programs on diabetes care. Health Policy 2009; 90 (2-3); 140148.

Mannion R, Goddard M, Bate A. Aligning incentives and motivations in health care: the case of earned autonomy. Financial Accountability \& Management 2007; 23 (4); 401-20.

McDonald R, Harrison S, Checkland K. Incentives and control in primary health care: findings from English pay-for-performance case studies. Journal of Health Organization and Management 2008; 22; $48-62$.

Mullen KJ, Frank RG, Rosenthal MB. Can you get what you pay for? Pay-for-performance and the quality of healthcare providers. Rand Journal of Economics 2010; 41 (1): 4-91.

Purdy S, Griffin T, Salisbury C, Sharp D. Ambulatory care sensitive conditions: terminology and disease coding need to be more specific to aid policy makers and clinicians. Public Health 2009; 123 (2); 169-173.

RACGP (Royal Australian College of General Practitioners). Diabetes Management in General Practice ( $15^{\text {th }}$ edition); 2009.

Scott A, Schurer S, Jensen PH, Sivey P. The effects of an incentive program on quality of care in diabetes management. Health Economics 2009; 18 (9); 1091-1108.

Siciliani L. Paying for performance and motivation crowding out. Economic Letters 2009; 103; 8-71.

Smith P. Measuring health system performance. European Journal of Health Economics 2002; 3; 145 48. 
Sutton M, Elder R, Guthrie B, Watt G. Record rewards: the effects of targeted quality incentives on the recording of risk factors by primary care providers. Health Economics 2010: 19; 1-13.

Van Herck P, De Smedt D, Annemans L et al. Systematic review: effects, design choices, and context of pay-for-performance in health care. BMC Health Services Research 2010: 10; 247-0.

Vuong Q. Likelihood ratio tests for model selection and non-nested hypothesis. Econometrica 1989: $57 ; 307-344$

Whalley D, Gravelle H and Sibbald B. Effect of the new contract on GPs' working lives and perceptions of quality of care: a longitudinal survey. British Journal of General Practice 2008; 58; 814.

Winkelmann R. Econometric analysis of count data - 4. ed. - Springer, Berlin; 2003.

Young GJ, Meterko M, Beckman $\mathrm{H}$ et al. Effects of paying physicians based on their relative performance for quality. General Internal Medicine 2007; 22; 872-876. 
Table 1 - Frequency distribution of diabetic ACSCs in GP's list

\begin{tabular}{|c|c|c|c|c|c|c|c|c|c|c|c|}
\hline $\begin{array}{l}\text { TOTAL } \\
\text { ACSCS }\end{array}$ & $\begin{array}{l}\text { Freq. } \\
\text { GP }\end{array}$ & Perc. & Cum. & \begin{tabular}{|r|} 
Long-term \\
complications \\
\end{tabular} & $\begin{array}{l}\text { Freq. } \\
\text { GP }\end{array}$ & Perc. & Cum. & \begin{tabular}{|r|}
$\begin{array}{r}\text { Short-term } \\
\text { complications }\end{array}$ \\
\end{tabular} & $\begin{array}{l}\text { Freq. } \\
\text { GP }\end{array}$ & Perc. & Cum. \\
\hline 0 & 5264 & $60 \%$ & $60 \%$ & 0 & 5269 & $60 \%$ & $60 \%$ & 0 & 6343 & $73 \%$ & $73 \%$ \\
\hline $1-4$ & 1944 & $22 \%$ & $83 \%$ & 1 & 23 & $0 \%$ & $61 \%$ & 1 & 1838 & $21 \%$ & $94 \%$ \\
\hline $5-8$ & 814 & $9 \%$ & $92 \%$ & 2 & 143 & $2 \%$ & $62 \%$ & 2 & 400 & $5 \%$ & $98 \%$ \\
\hline $9-12$ & 338 & $4 \%$ & $96 \%$ & 3 & 610 & $7 \%$ & $69 \%$ & 3 & 65 & $1 \%$ & $99 \%$ \\
\hline $13-16$ & 180 & $2 \%$ & $98 \%$ & 4 & 1197 & $14 \%$ & $83 \%$ & 4 & 52 & $1 \%$ & $100 \%$ \\
\hline $17-20$ & 91 & $1 \%$ & $99 \%$ & 5 & 13 & $0 \%$ & $83 \%$ & 5 & 15 & $0 \%$ & $100 \%$ \\
\hline $21-24$ & 43 & $0 \%$ & $99 \%$ & 6 & 82 & $1 \%$ & $84 \%$ & 6 & 10 & $0 \%$ & $100 \%$ \\
\hline $25-28$ & 27 & $0 \%$ & $100 \%$ & 7 & 244 & $3 \%$ & $87 \%$ & $>6$ & 3 & $0 \%$ & $100 \%$ \\
\hline $29-32$ & 13 & $0 \%$ & $100 \%$ & 8 & 460 & $5 \%$ & $92 \%$ & & & & \\
\hline \multirow[t]{5}{*}{$>32-$} & 12 & $0 \%$ & $100 \%$ & 9 & 9 & $0 \%$ & $92 \%$ & & & & \\
\hline & & & & 10 & 29 & $0 \%$ & $93 \%$ & & & & \\
\hline & & & & $11-20$ & 559 & $6 \%$ & 99\% & & & & \\
\hline & & & & $21-30$ & 65 & $1 \%$ & $100 \%$ & & & & \\
\hline & & & & $>30$ & 23 & $0 \%$ & $100 \%$ & & & & \\
\hline $\begin{array}{c}\text { Tot } \\
\text { Yearly }\end{array}$ & & & & Yearly L-T & & & & & & & \\
\hline ACSC & Tot & & & ACSCS & Tot & & & Yearly S-T & Tot & & \\
\hline 8942 & GPs & 8726 & & 7874 & GPs & 8726 & & ACSCs 1069 & GPs & 8726 & \\
\hline
\end{tabular}


Table 2 - Descriptive Statistics, GP characteristics year 2003-2005

\begin{tabular}{|c|c|c|c|c|c|c|}
\hline & Variable & & Mean & Std. Dev. & Min & Max \\
\hline \multirow[t]{3}{*}{ OUTCOME } & TOTAL ACSCS & & 3.074375 & 4.937671 & 0 & 52 \\
\hline & Long-term complications & & 2.706968 & 4.767965 & 0 & 48 \\
\hline & Short-term complications & & 0.367408 & 0.735984 & 0 & 13 \\
\hline \multirow{11}{*}{$\begin{array}{l}\text { Time-variant } \\
\text { variables }\end{array}$} & GP seniority & & 18.18 & 7.80 & 0.06 & 45.17 \\
\hline & List Avg. Age & & 47.39 & 5.23 & 12.27 & 75.55 \\
\hline & List size & & 1164.01 & 376.03 & 10 & 1887 \\
\hline & List diabetic size & & 52.62 & 22.47 & 1 & 128 \\
\hline & Insulin patients & & 8.15 & 4.66 & 0 & 29 \\
\hline & Specialist visits & & 48.21 & 40.35 & 0 & 255 \\
\hline & Practice type & Associated=1 & 0.68 & 0.47 & 0 & 1 \\
\hline & Financial Incentives & & 0.70 & 1.33 & 0 & 8.98 \\
\hline & Hospital beds by population & & 0.48 & 0.10 & 0.06 & 0.68 \\
\hline & District population density & & 1029.58 & 1748.28 & 82.54 & 6176.36 \\
\hline & Competition index & & 0.82 & 0.13 & 0.68 & 1.99 \\
\hline \multirow{7}{*}{$\begin{array}{l}\text { Time-invariant } \\
\text { variables }\end{array}$} & Postgraduate qualification & (if yes=1) & 0.05 & 0.22 & 0 & 1 \\
\hline & GP gender & (Male=1) & 0.76 & 0.42 & 0 & 1 \\
\hline & Practice rural location & (if yes=1) & 0.06 & 0.23 & 0 & 1 \\
\hline & LHA1 & & 0.43 & 0.49 & 0 & 1 \\
\hline & LHA2 & & 0.32 & 0.43 & 0 & 1 \\
\hline & LHA3 & & 0.25 & 0.44 & 0 & 1 \\
\hline & Beds in endocrinology & (if yes=1) & 0.64 & 0.48 & 0 & 1 \\
\hline
\end{tabular}


Figure 1 - Financial incentives in \% GP annual income. LHAs, years 2003-2005

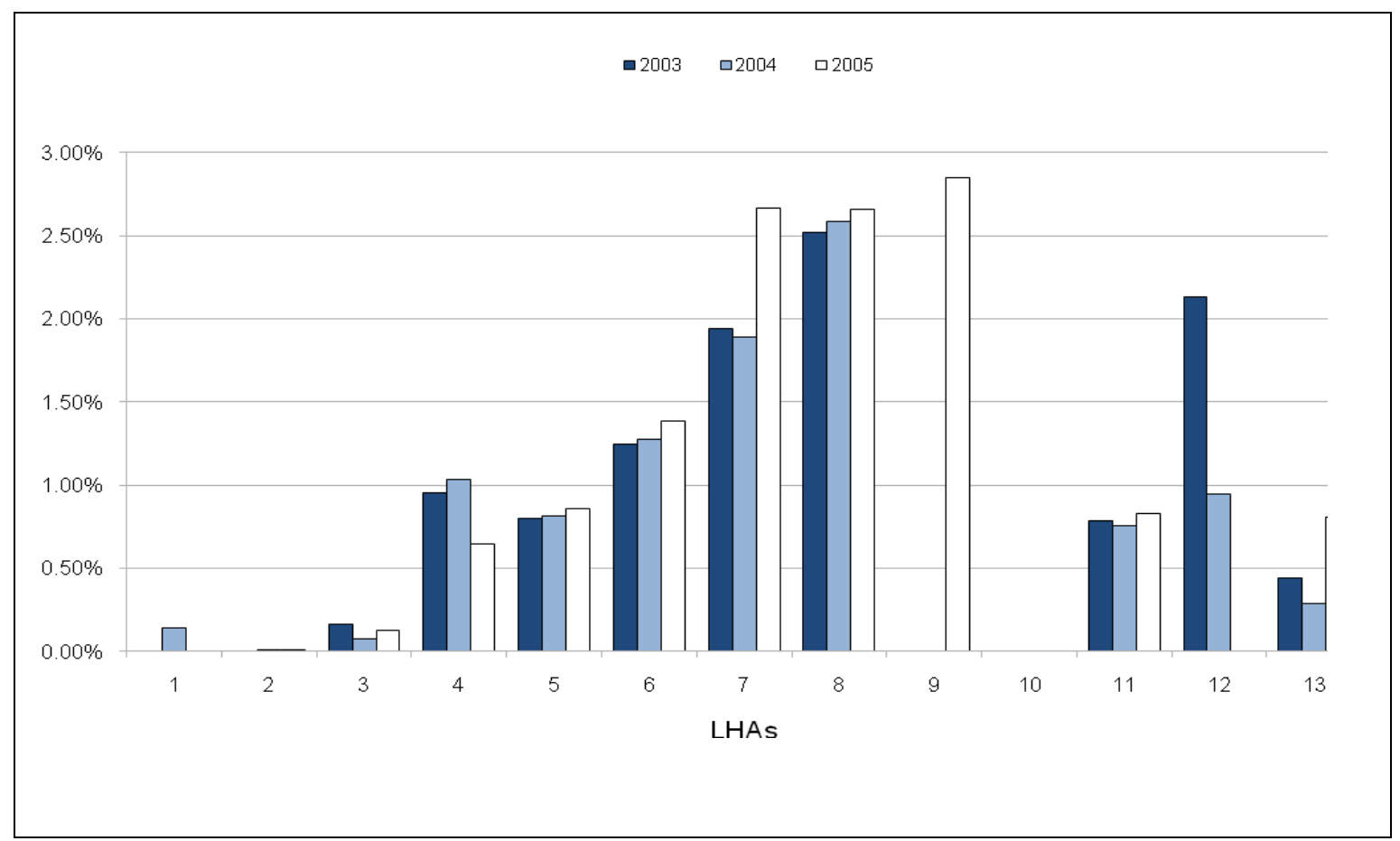

Figure 2 - Density histogram of dependent variable with normal line. Years 2003-2005
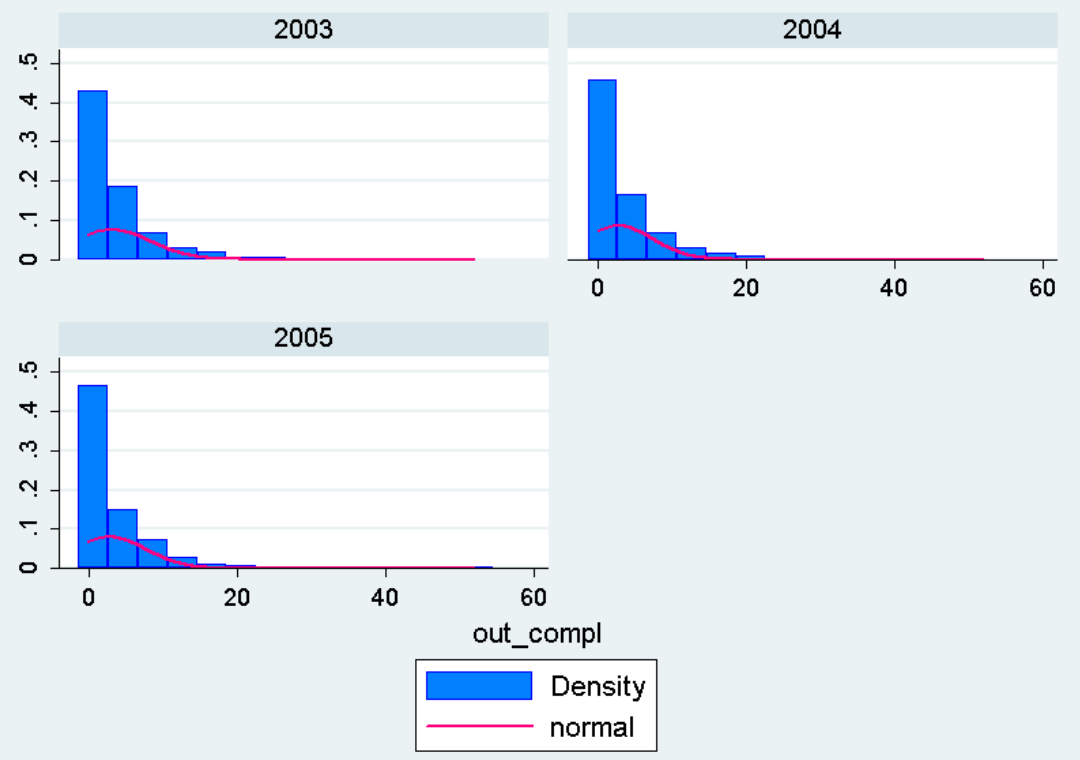
Table 3 - Likelihood-ratio and Vuong test

\begin{tabular}{ccccc}
\hline Restricted & Unrestricted & LR test & Prob>chi2 & The best \\
\hline Poisson & NB2 & 1199.98 & $6.1609 \mathrm{E}-263$ & NB2 \\
NB1 & NBP & 11.048 & 0.001 & NB1 \\
NB2 & NBP & 2.332 & 0.127 & NB2 \\
\multicolumn{2}{c}{ Compare } & VUONG & |Prob|>NormSt & The best \\
NB1 vs NB2 & -2.76 & 0.002 & NB2 \\
Restricted & Unrestricted & LR test & Prob>chi2 & The best \\
Pool & RE & 358.656 & $1.315 E-78$ & RE \\
\hline
\end{tabular}


Table 4 - Total diabetes ACSCs in GP's list. Year 2003-2005.

\begin{tabular}{lrlrlrl}
\hline TOTAL DIABETES ACSCS & \multicolumn{2}{c}{ NB Pool } & \multicolumn{2}{c}{ NB RE } & \multicolumn{2}{c}{ NB FE } \\
\hline & coefficient & $p$ value & coefficient & $p$ value & coefficient & $p$ value \\
\cline { 2 - 6 } GP seniority & 0.006 & $(0.048)$ & 0.006 & $(0.016)$ & -0.000 & $(0.957)$ \\
List Avg. Age & 0.019 & $(0.001)$ & 0.017 & $(0.000)$ & 0.014 & $(0.136)$ \\
List size & 0.000 & $(0.105)$ & 0.000 & $(0.035)$ & 0.000 & $(0.599)$ \\
List diabetic size & 0.012 & $(0.000)$ & 0.012 & $(0.000)$ & 0.007 & $(0.038)$ \\
Insulin patients & 0.040 & $(0.000)$ & 0.036 & $(0.000)$ & 0.040 & $(0.000)$ \\
Specialist visits & -0.000 & $(0.535)$ & -0.001 & $(0.030)$ & -0.002 & $(0.103)$ \\
Practice type & 0.034 & $(0.491)$ & 0.048 & $(0218)$ & -0.017 & $(0.809)$ \\
Financial Incentives & $-\mathbf{0 . 0 8 8}$ & $(\mathbf{0 . 0 0 0 )}$ & $-\mathbf{0 . 0 8 6}$ & $\mathbf{( 0 . 0 0 0 )}$ & $-\mathbf{0 . 0 5 7}$ & $\mathbf{( 0 . 0 1 4 )}$ \\
Hospital beds by population & -0.053 & $(0.840)$ & 0.111 & $(0.594)$ & 0.407 & $(0.046)$ \\
District population density & -0.000 & $(0.001)$ & -0.000 & $(0.000)$ & -0.000 & $(0.003)$ \\
Competition index & -0.167 & $(0.275)$ & -0.045 & $(0.718)$ & -0.048 & $(0.735)$ \\
Postgraduate qualification & 0.33 & $(0.000)$ & 0.288 & $(0.000)$ & & \\
GP gender & -0.087 & $(0.111)$ & -0.013 & $(0.710)$ & & \\
Practice rural location & 0.070 & $(0.432)$ & 0.084 & $(0.228)$ & & \\
LHA1 & 0.032 & $(0.694)$ & 0.094 & $(0.130)$ & & \\
LHA3 & -0.055 & $(0.498)$ & -0.066 & $(0.303)$ & & \\
Beds in endocrinology & 0.224 & $(0.000)$ & 0.104 & $(0.016)$ & & \\
year (2004) & -0.142 & $(0.005)$ & -0.149 & $(0.000)$ & -0.108 & $(0.011)$ \\
year (2005) & -0.071 & $(0.190)$ & -0.085 & $(0.059)$ & -0.026 & $(0.587)$ \\
Constant & -0.848 & $(0.021)$ & -2.965 & $(0.000)$ & -2.143 & $(0.000)$ \\
Inalpha & 0.946 & $(0.000)$ & & & & \\
In_r & & & 3.589 & $(0.000)$ & & \\
In_S & & & 5.692 & $(0.000)$ & & \\
\hline HAUSMAN & Chi2(13)= & $\mathbf{1 9 6}$ & $\mathbf{P}$ value & $\mathbf{0 . 0 0 0}$ & & \\
\hline & & & & & &
\end{tabular}


Table 5.a - Long-term complications in GP's list. Year 2003-2005.

\begin{tabular}{lcccccc}
\hline Long-term complications & \multicolumn{2}{c}{ NB Pool } & \multicolumn{2}{c}{ NB RE } & \multicolumn{2}{c}{ NB FE } \\
& coefficient & $p$ value & coefficient & $p$ value & coefficient & $p$ value \\
GP seniority & 0.007 & $(0.042)$ & 0.008 & $(0.006)$ & 0.001 & $(0.833)$ \\
List Avg. Age & 0.021 & $(0.001)$ & 0.022 & $(0.000)$ & 0.033 & $(0.003)$ \\
List size & $1.43 E-04$ & $(0.246)$ & $1.50 E-04$ & $(0.137)$ & $9.60 \mathrm{E}-05$ & $(0.635)$ \\
List diabetic size & 0.012 & $(0.000)$ & 0.012 & $(0.000)$ & 0.004 & $(2.280)$ \\
Insulin patients & 0.042 & $(0.000)$ & 0.033 & $(0.000)$ & 0.026 & $(0.019)$ \\
Specialist visits & $1.64 \mathrm{E}-06$ & $(0.998)$ & 0.000 & $(0.446)$ & $2.53 \mathrm{E}-04$ & $(0.809)$ \\
Practice type & 0.051 & $(0.341)$ & 0.084 & $(0.061)$ & -0.038 & $(0.632)$ \\
Financial Incentives & -0.084 & $(0.001)$ & -0.091 & $(0.000)$ & -0.066 & $(0.014)$ \\
Hospital beds by population & -0.072 & $(0.798)$ & 0.097 & $(0.681)$ & 0.376 & $(0.102)$ \\
District population density & $-3.19 \mathrm{E}-04$ & $(0.002)$ & $-4.35 \mathrm{E}-04$ & $(0.000)$ & -0.001 & $(0.000)$ \\
Competition index & -0.153 & $(0.368)$ & -0.005 & $(0.974)$ & 0.008 & $(0.962)$ \\
Postgraduate qualification & 0.356 & $(0.001)$ & 0.314 & $(0.000)$ & & \\
GP gender & -0.101 & $(0.096)$ & $3.84 \mathrm{E}-03$ & $(0.939)$ & & \\
Practice rural location & 0.041 & $(0.675)$ & 0.051 & $(0.524)$ & & \\
LHA1 & 0.003 & $(0.971)$ & 0.051 & $(0.465)$ & & \\
LHA3 & -0.054 & $(0.545)$ & -0.093 & $(0.199)$ & & \\
Beds in endocrinology & 0.274 & $(0.000)$ & 0.153 & $(0.002)$ & & \\
year (2004) & -0.124 & $(0.027)$ & -0.120 & $(0.012)$ & -0.088 & $(0.074)$ \\
year (2005) & -0.051 & $(0.393)$ & -0.060 & $(0.250)$ & 0.004 & $(0.937)$ \\
Constant & -1.082 & $(0.007)$ & -3.687 & $(0.000)$ & -3.307 & $(0.000)$ \\
Inalpha & 1.345 & $(0.000)$ & & & & \\
In_r & & & 13.510 & $(0.882)$ & & \\
In_S & & & 15.950 & $(0.861)$ & & \\
\hline
\end{tabular}


Table 5.b: Short-term complications in GP's list. Year 2003-2005.

\begin{tabular}{lrlrlrl}
\hline Short-term complications & \multicolumn{2}{c}{ NB Pool } & \multicolumn{2}{c}{ NB RE } & \multicolumn{2}{c}{ NB FE } \\
& coefficient & $p$ value & coefficient & $p$ value & coefficient & $p$ value \\
GP seniority & -0.002 & $(0.643)$ & -0.001 & $(0.813)$ & 0.013 & $(0.458)$ \\
List Avg. Age & 0.004 & $(0.574)$ & 0.004 & $(0.547)$ & -0.113 & $(0.279)$ \\
List size & $3.83 \mathrm{E}-04$ & $(0.003)$ & $4.40 \mathrm{E}-04$ & $(0.001)$ & $-5.57 \mathrm{E}-04$ & $(0.278)$ \\
List diabetic size & 0.013 & $(0.000)$ & 0.012 & $(0.000)$ & 0.022 & $(0.039)$ \\
Insulin patients & 0.031 & $(0.000)$ & 0.033 & $(0.000)$ & 0.074 & $(0.026)$ \\
Specialist visits & $-3.91 \mathrm{E}-03$ & $(0.000)$ & -0.004 & $(0.000)$ & $-5.22 \mathrm{E}-03$ & $(0.291)$ \\
Practice type & -0.056 & $(0.370)$ & -0.048 & $(0.422)$ & 0.103 & $(0.482)$ \\
Financial Incentives & -0.102 & $(0.000)$ & -0.095 & $(0.001)$ & -0.075 & $(0.060)$ \\
Hospital beds by population & -0.023 & $(0.937)$ & 0.016 & $(0.961)$ & 0.091 & $(0.804)$ \\
District population density & $-6.27 \mathrm{E}-05$ & $(0.477)$ & $-8.61 \mathrm{E}-05$ & $(0.405)$ & -0.001 & $(0.064)$ \\
Competition index & -0.218 & $(0.207)$ & -0.123 & $(0.515)$ & 0.150 & $(0.503)$ \\
Postgraduate qualification & 0.186 & $(0.079)$ & 0.183 & $(0.105)$ & & \\
GP gender & -0.053 & $(0.429)$ & $-4.79 \mathrm{E}-02$ & $(0.470)$ & & \\
Practice rural location & 0.162 & $(0.077)$ & 0.198 & $(0.047)$ & & \\
LHA1 & 0.366 & $(0.000)$ & 0.359 & $(0.000)$ & & \\
LHA3 & -0.047 & $(0.645)$ & -0.056 & $(0.587)$ & & \\
Beds in endocrinology & -0.149 & $(0.021)$ & -0.134 & $(0.039)$ & & \\
year (2004) & -0.260 & $(0.000)$ & -0.255 & $(0.000)$ & -0.115 & $(0.340)$ \\
year (2005) & -0.204 & $(0.003)$ & -0.182 & $(0.003)$ & -0.215 & $(0.080)$ \\
Constant & -2.069 & $(0.000)$ & -0.446 & $(0.332)$ & 5.464 & $(0.289)$ \\
Inalpha & -0.392 & $(0.005)$ & & & & \\
In_r & & & 3.416 & $(0.000)$ & & \\
In_S & & & 1.605 & $(0.000)$ & & \\
\hline & & & & & &
\end{tabular}


Table 6 - Marginal effects of additional amounts of financial incentives on the expected number of avoidable ACSCs

\begin{tabular}{|c|c|c|c|c|c|}
\hline $\begin{array}{c}\text { Financial } \\
\text { Incentives (\% } \\
\text { annual income) }\end{array}$ & $\begin{array}{l}\text { Marginal } \\
\text { effects }\end{array}$ & $\begin{array}{c}\text { Average } \\
\text { Financial } \\
\text { incentives (in } € \text { ) }\end{array}$ & $\begin{array}{c}\text { Predicted } \\
\text { number of } \\
\text { avoidable } \\
\text { ACSCs per GP }\end{array}$ & $\begin{array}{l}\text { Total predicted } \\
\text { no. of avoidable } \\
\text { ACSCs }\end{array}$ & $\begin{array}{l}\text { Predicted } \\
\text { reduction of } \\
\text { ACSCs }\end{array}$ \\
\hline 0.69576 & -0.243 & 588.23 & 2.81 & 8165 & - \\
\hline \multicolumn{6}{|c|}{ Simulation for an increase of 100 euros per capita (from 588 to 688 euros) } \\
\hline 0.81404 & -0.236 & 688.23 & 2.73 & 7943 & 222 \\
\hline \multicolumn{6}{|c|}{ Simulation for an increase of 200 euros per capita (from 588 to 788 euros) } \\
\hline 0.93232 & -0.234 & 788.23 & 2.70 & 7862 & 303 \\
\hline \multicolumn{6}{|c|}{ Simulation for an increase of 1000 euros per capita (from 588 to 1588 euros) } \\
\hline 1.87856 & -0.216 & 1588.23 & 2.49 & 7244 & 921 \\
\hline
\end{tabular}


Table 7 - Quadratic effects for total diabetes ACSCs

\begin{tabular}{lrlrlrl}
\hline TOTAL DIABETES ACSCS & \multicolumn{2}{c}{ NB Pool } & \multicolumn{2}{c}{ NB RE } & \multicolumn{2}{c}{ NB FE } \\
& coefficient & $p$ value & coefficient & $p$ value & coefficient & $p$ value \\
GP seniority & 0.006 & $(0.074)$ & 0.006 & $(0.030)$ & -0.000 & $(0.919)$ \\
List Avg. Age & 0.017 & $(0.003)$ & 0.014 & $(0.003)$ & 0.013 & $(0.159)$ \\
List size & 0.000 & $(0.342)$ & 0.000 & $(0.416)$ & 0.000 & $(0.792)$ \\
List diabetic size & 0.012 & $(0.000)$ & 0.012 & $(0.000)$ & 0.006 & $(0.048)$ \\
Insulin patients & 0.113 & $(0.000)$ & 0.113 & $(0.000)$ & 0.099 & $(0.001)$ \\
Insulin patients^2 & -0.003 & $(0.000)$ & -0.003 & $(0.000)$ & -0.003 & $(0.032)$ \\
Specialist visits & -0.000 & $(0.410)$ & -0.001 & $(0.016)$ & -0.002 & $(0.089)$ \\
Practice type & 0.034 & $(0.487)$ & 0.042 & $(0.281)$ & -0.016 & $(0.820)$ \\
Financial Incentives & -0.091 & $(0.000)$ & -0.087 & $(0.000)$ & -0.057 & $(\mathbf{0 . 0 1 4})$ \\
Hospital beds by population & -0.051 & $(0.848)$ & 0.117 & $(0.573)$ & 0.410 & $(0.044)$ \\
District population density & -0.000 & $(0.003)$ & -0.000 & $(0.000)$ & -0.000 & $(0.005)$ \\
Competition index & -0.174 & $(0.273)$ & -0.078 & $(0.530)$ & -0.058 & $(0.680)$ \\
Postgraduate qualification & 0.332 & $(0.000)$ & 0.300 & $(0.000)$ & & \\
GP gender & -0.085 & $(0.121)$ & -0.006 & $(0.888)$ & & \\
Practice rural location & 0.063 & $(0.490)$ & 0.0657 & $(0.348)$ & & \\
LHA1 & 0.029 & $(0.720)$ & 0.088 & $(0.155)$ & & \\
LHA3 & -0.058 & $(0.480)$ & -0.068 & $(0.293)$ & & \\
Beds in endocrinology & 0.217 & $(0.000)$ & 0.096 & $(0.025)$ & & \\
year (2004) & -0.140 & $(0.006)$ & -0.144 & $(0.001)$ & -0.106 & $(0.012)$ \\
year (2005) & -0.069 & $(0.204)$ & -0.083 & $(0.064)$ & -0.026 & $(0.593$ \\
Constant & -0.941 & $(0.010$ & -2.987 & $(0.000)$ & -2.287 & $(0.000)$ \\
Lnalpha & 0.942 & $(0.000)$ & & & & \\
In_r & & & 3.619 & $(0.000)$ & & \\
In_s & & & 5.720 & $(0.000$ & & \\
\hline & & & & & &
\end{tabular}


Table 8 - DRG expenditure for total diabetes ACSCs

\begin{tabular}{|c|c|c|c|c|c|c|c|c|}
\hline \multirow[t]{2}{*}{ TOTAL DIABETES ACSCS } & \multicolumn{2}{|c|}{ Pool } & \multicolumn{2}{|c|}{ RE } & \multicolumn{2}{|c|}{ FE } & \multicolumn{2}{|c|}{ Hausman Taylor } \\
\hline & coefficient & $p$ value & coefficient & $p$ value & coefficient & $p$ value & coefficient & $p$ value \\
\hline GP seniority & 0.015 & $(0.058)$ & 0.016 & $(0.069)$ & 0.013 & $(0.093)$ & 0.009 & $(0.437)$ \\
\hline List Avg. Age & 0.033 & $(0.003)$ & 0.034 & $(0.010)$ & 0.031 & $(0.010)$ & 0.087 & $(0.000)$ \\
\hline List size & $-8.42 \mathrm{E}-05$ & $(0.749)$ & $-2.97 \mathrm{E}-05$ & $(0.917)$ & $-1.21 \mathrm{E}-04$ & $(0.647)$ & 0.002 & $(0.003)$ \\
\hline List diabetic size & 0.036 & $(0.000)$ & 0.035 & $(0.000)$ & 0.035 & $(0.000)$ & -0.011 & $(0.552)$ \\
\hline Insulin patients & 0.099 & $(0.000)$ & 0.098 & $(0.000)$ & 0.105 & $(0.000)$ & 0.045 & $(0.544)$ \\
\hline Specialist visits & -0.001 & $(0.370)$ & -0.001 & $(0.407)$ & 0.000 & $(0.866)$ & 0.002 & (0.799) \\
\hline Practice type & 0.213 & $(0.078)$ & 0.203 & $(0.118)$ & 0.137 & $(0.259)$ & 0.051 & $(0.862)$ \\
\hline Financial Incentives & -0.231 & $(0.000)$ & -0.218 & $(0.000)$ & -0.208 & $(0.000)$ & -0.134 & (0.039) \\
\hline Hospital beds by population & 0.009 & (0.989) & 0.186 & $(0.755)$ & 0.296 & $(0.585)$ & 0.735 & (0.192) \\
\hline District population density & -0.001 & $(0.000)$ & -0.001 & $(0.000)$ & -0.001 & $(0.000)$ & -0.001 & $(0.001)$ \\
\hline Competition index & -0.007 & $(0.988)$ & 0.023 & (0.959) & 0.250 & $(0.526)$ & 0.373 & $(0.395)$ \\
\hline Postgraduate qualification & 0.579 & $(0.021)$ & 0.552 & $(0.041)$ & & & 0.439 & (0.173) \\
\hline GP gender & -0.026 & $(0.839)$ & -0.035 & $(0.804)$ & & & 0.098 & $(0.570)$ \\
\hline Practice rural location & 0.035 & $(0.878)$ & 0.051 & $(0.838)$ & & & 0.255 & $(0.423)$ \\
\hline LHA1 & 0.035 & $(0.858)$ & 0.042 & $(0.840)$ & & & -0.106 & $(0.772)$ \\
\hline LHA3 & -0.404 & $(0.041)$ & -0.379 & $(0.073)$ & & & -0.479 & $(0.128)$ \\
\hline Beds in endocrinology & 0.202 & $(0.126)$ & 0.227 & $(0.104)$ & & & 0.313 & $(0.112)$ \\
\hline year (2004) & -0.221 & $(0.098)$ & -0.214 & $(0.093)$ & -0.181 & $(0.173)$ & -0.222 & $(0.064)$ \\
\hline year (2005) & -0.066 & $(0.643)$ & -0.047 & $(0.732)$ & -0.019 & $(0.895)$ & -0.060 & $(0.657)$ \\
\hline Constant & -0.448 & $(0.573)$ & -0.661 & $(0.439)$ & -0.685 & $(0.318)$ & -3.606 & $(0.003)$ \\
\hline
\end{tabular}


Table 9 - Marker conditions in GP's list. Year 2003-2005.

\begin{tabular}{lrrrrrr}
\hline MARKER CONDITIONS & \multicolumn{2}{c}{ NB Pool } & \multicolumn{2}{c}{ NB RE } & \multicolumn{2}{c}{ NB FE } \\
& coefficient & $p$ value & coefficient & $p$ value & coefficient & $p$ value \\
GP seniority & 0.005 & $(0.049)$ & 0.009 & $(0.048)$ & -0.001 & $(0.642)$ \\
List Avg. Age & 0.013 & $(0.005)$ & 0.012 & $(0.107)$ & $-1.71 \mathrm{E}-04$ & $(0.965)$ \\
List size & $3.89 \mathrm{E}-05$ & $(0.620)$ & $9.25 \mathrm{E}-05$ & $(0.537)$ & $-2.09 \mathrm{E}-04$ & $(0.006)$ \\
List diabetic size & 0.019 & $(0.000)$ & 0.020 & $(0.000)$ & 0.007 & $(0.000)$ \\
Insulin patients & 0.001 & $(0.872)$ & 0.000 & $(0.997)$ & 0.004 & $(0.401)$ \\
Specialist visits & 0.001 & $(0.041)$ & 0.001 & $(0.354)$ & 0.001 & $(0.065)$ \\
Practice type & 0.089 & $(0.011)$ & 0.069 & $(0.255)$ & 0.063 & $(0.066)$ \\
Financial Incentives & $\mathbf{0 . 0 1 0}$ & $(0.469)$ & $\mathbf{0 . 0 0 2}$ & $(0.937)$ & $\mathbf{0 . 0 0 1}$ & $(0.939)$ \\
Hospital beds by population & 0.248 & $(0.172)$ & 0.128 & $(0.491)$ & 0.226 & $(0.138)$ \\
District population density & $-5.12 \mathrm{E}-06$ & $(0.916)$ & $2.92 \mathrm{E}-06$ & $(0.978)$ & $-1.09 \mathrm{E}-05$ & $(0.810)$ \\
Competition index & -0.365 & $(0.014)$ & -0.088 & $(0.593)$ & -0.365 & $(0.006)$ \\
Postgraduate qualification & -0.016 & $(0.846)$ & -0.030 & $(0.809)$ & & \\
GP gender & -0.046 & $(0.235)$ & -0.042 & $(0.510)$ & & \\
Practice rural location & 0.079 & $(0.185)$ & 0.048 & $(0.693)$ & & \\
LHA1 & 0.143 & $(0.009)$ & 0.150 & $(0.159)$ & & \\
LHA3 & 0.127 & $(0.020)$ & 0.113 & $(0.288)$ & & \\
Beds in endocrinology & -0.090 & $(0.014)$ & -0.055 & $(0.374)$ & & \\
year (2004) & -0.039 & $(0.281)$ & -0.023 & $(0.539)$ & -0.024 & $(0.504)$ \\
year (2005) & 0.036 & $(0.359)$ & 0.053 & $(0.200)$ & 0.017 & $(0.660)$ \\
Constant & -2.005 & $(0.000)$ & 14.350 & $(0.885)$ & 0.367 & $(0.105)$ \\
Inalpha & -3.407 & $(0.000)$ & & & & \\
In_r & & & 16.300 & $(0.870)$ & & \\
In_s & & & -0.414 & $(0.000)$ & & \\
\hline
\end{tabular}




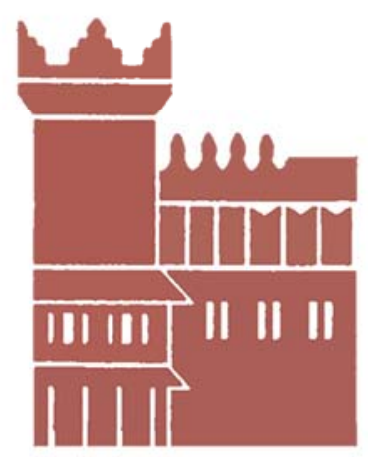

Alma Mater Studiorum - Università di Bologna DEPARTMENT OF ECONOMICS

Strada Maggiore 45

40125 Bologna - Italy

Tel. +39051 2092604

Fax +390512092664

http://www.dse.unibo.it 